\title{
Levantamento e distribuição das espécies de Teredinidae (Mollusca - Bivalvia) no manguezal da Praia Dura, Ubatuba, São Paulo, Brasil
}

\author{
Sônia Godoy Bueno Carvalho LOPES \& Walter NARCHI \\ Departamento de Zoologia, Instituto de Biociências da Universidade de São Paulo \\ (Caixa Postal 20520, 01452-990 São Paulo, SP, Brasil)
}

\begin{abstract}
- Abstract: A survey for bivalves (Teredinidae) at several sites in the Escuro River and Comprido River at mangrove regions in Praia Dura, Ubatuba, SP was conducted. Nausitora fusticula was the most abundant species found in all collection sites at the border of Comprido River meaning that the species was well adapted to the intertidal regions and to the large variation in salinity (0 to $33 \mathrm{~S})$. N. fusticula was found with Bankia fimbriatula, Bankia gouldi and Bankia rochi at the mangrove region in contact with the water. At the regions less influenced by the tides $N$. fusticula occurred with Neoteredo reynei and few specimens of the genus Bankia already cited. The species of Teredinidae was found at the maximum limit of penetration of the sea water during the high tides. When the salinity was lower neither Bankia species nor Neoteredo reynei occurred, but Psiloteredo healdi and $N$. fusticula were found.
\end{abstract}

- Resumo: Realizou-se o levantamento e estudou-se a distribuição das espécies de Teredinidae no manguezal da Praia Dura, Ubatuba, São Paulo, Brasil. Investigou-se a abundância das espécies nas regiōes mais em contato freqüente com a água e as menos atingidas pelas preamares. Determinou-se, também, a distribuiçāo das espécies ao longo do Rio Escuro, segundo um gradiente decrescente de salinidade: Nausitora fusticula foi a espécie mais abundante ao longo do Rio Comprido, demonstrando que esta espécie está bem adaptada a região entremarés e a grande variação de salinidade ( 0 a $33 \mathrm{~S}$ ). $\mathrm{Na}$ área do bosque em maior contato com a água $N$. fusticula é encontrada com Bankia fimbriatula, B. gouldi e B. rochi e, nas áreas menos atingidas pelas preamares, divide o ambiente com Neoteredo reynei, ocorrendo poucos indivíduos das espécies de Bankia já mencionadas. O limite máximo da ocorrência de Teredinidae no Rio Comprido, correspondeu ao limite máximo da penetração da água do mar durante as preamares. Nas áreas menos salinas do rio, praticamente deixam de ocorrer todas as espécies de Bankia e Neoteredo reynei, começando a surgir Psiloteredo healdi, com quem $N$. fusticula passa a dividir $o$ ambiente, sendo posteriormente dominada por aquela.

- Descriptors: Teredinidae, Intertidal environment, Mangrove, Species diversity, Dominant species, Geographical distribution, Salinity effects, Temperature effects, Ubatuba, São Paulo, Brazil.

- Descritores: Teredinidae, Ambiente entremarés, Manguezal, Diversidade das espécies, Espécies dominantes, Distribuiçāo geográfica, Efeitos da salinidade, Efeitos da temperatura, Ubatuba: SP, Brasil.

\section{Introdução}

Os Teredinidae estão amplamente distribuídos em todos os oceanos, sendo, no entanto, mais abundantes nas regiōes tropicais, onde ocorrem mais de $2 / 3$ das 69 espécies atualmente reconhecidas como válidas (Hoagland \&
Turner, 1981). No Brasil, há registro de 25 espécies de Teredinidae, conforme se pôde compilar com base nos trabalhos de Bartsch (1922), Clench \& Turner (1946), Turner (1966, 1971a), Abbott (1974), Boffi (1979), Rios (1985), Müller \& Lana (1986, 1987), Martins-Silva et al. (1988), Junqueira et al. (1989), Silva et al. (1989), 
Martins-Silva et al. (1990), Omena et al. (1990) e Junqueira \& Silva (1991), que citam espécies que ocorrem no litoral brasileiro.

A distribuição dos Teredinidae está relacionada basicamente à disponibilidade de madeira, salinidade e temperatura.

A madeira constitui o estímulo para o assentamento larval. Não estando presente no meio, a fase larval livre-natante é prolongada por alguns dias (Turner, 1984).

A temperatura e a salinidade são fatores que apresentam complexa correlaçāo entre si, podendo a temperatura alterar a tolerância dos organismos em relaçâo à salinidade (Kinne, 1963). A tolerância de uma mesma espécie a diferentes salinidades difere de acordo com a localização geográfica e a temperatura predominante na região, podendo variar inclusive num mesmo local em funçāo das oscilaçōes da temperatura ao longo das estaçōes do ano (Nair \& Saraswathy, 1971). Revisão dos dados referentes aos efeitos da salinidade e temperatura na tolerância de diversas espécies de Teredinidae, em diferentes locais do mundo, foi apresentada por Eckelbarger \& Reish (1972).

Em regiōes estuarinas, a salinidade parece ser o principal fator ecológico que afeta a distribuição dos Teredinidae (Saraswathy \& Nair, 1974; Turner, 1974; Rayner, 1979).

A temperatura e a salinidade, embora importantes para a sobrevivência dos adultos, têm influência maior sobre as larvas, pois estas requerem condiçōes ótimas com relação a essas variáveis, enquanto que os adultos toleram variações maiores com relação a esses fatores (Turner, 1966), podendo permanecer isolados no interior da madeira por uma semana ou mais (Lane, 1955).

O presente trabalho tem por objetivos o levantamento e o estudo da distribuição das espécies de Teredinidae no manguezal da Praia Dura, Ubatuba, SP, um ambiente estuarino pouco alterado pelo homem.

\section{Descrição da área}

Os bosques de mangue associados ao estuário dos rios Comprido e Escuro, que desembocam na Praia Dura, Ubatura, SP (Fig. 1), desenvolvem-se entre a linha das marés altas de sizígia e o nível próximo e acima do nível médio das marés, em local de baixo hidrodinamismo; ocupam uma área de $110.720 \mathrm{~m}^{2}$ (aproximadamente 11 hectares) que é considerada pequena quando comparada à ocupada por outros bosques existentes na costa brasileira (Herz, 1991).

A maior parte do bosque apresenta substrato arenoso compactado, entremeado por manchas de sedimento lodoso. A espécie vegetal predominante é Laguncularia racemosa, seguida de Avicennia schaueriana; Rhizophora mangle ocorre apenas nas manchas lodosas.

No Rio Escuro, o bosque de mangue está restrito à área próxima à sua desembocadura, enquanto que no Rio Comprido, avança ao longo de seu percurso, em direção ao continente, desenvolvendo-se nas margens onde há deposição de sedimento.

$\mathrm{Na}$ periferia dos bosques de mangue, desenvolve-se outra comunidade vegetal, denominada "de transição", composta principalmente por Hibiscus tiliaceus. Esta comunidade ocorre a partir do limite máximo atingido pela maré de sizígia e a partir do limite máximo de penetração da água do mar nos rios.

\section{Material e métodos}

Foram adotadas duas metodologias distintas, visando o conhecimento da distribuiçāo das espécies na área : em uma delas, procurou-se determinar a distribuição das espécies no bosque de mangue e, em outra, a distribuição ao longo de um gradiente decrescente de salinidade.

Para o estudo da distribuição das espécies no bosque de mangue foram realizadas dez coletas, no período de maio de 1984 a agosto de 1985 . Em cada uma delas, foram recolhidos troncos com Teredinidae em três regiōes do bosque assim definidas : região anterior ou marginal, mais próxima do curso dos rios na maré baixa e que é mais freqüentemente recoberta pela água nas preamares, mesmo com pequenas elevaçōes da maré; regiāo posterior, mais próxima da vegetação de transição e que é recoberta apenas em marés altas extremas; e região intermediária, com características intermediárias entre a anterior e a posterior (Fig. 1). Coletaram-se, sempre que possível, troncos grandes que, pela menor probabilidade de serem transportados durante as preamares, praticamente asseguravam terem sido colonizados no próprio local de origem. Removeram-se também, ramos ou raízes caidos, mas ainda ligados às árvores vivas.

Para o estudo da distribuição das espécies ao longo de um gradiente decrescente de salinidade foram realizadas sete coletas, no período de agosto de 1984 a agosto de 1985, ao longo de um trecho do Rio Comprido. Este rio foi escolhido por apresentar curso principal bem definido e sem ramificações. As coletas foram realizadas com auxilio de uma embarcação a remo, amostrando-se doze áreas, numeradas de 1 até 12 (Fig. 1), desde a foz até onde as espécies de Teredinidae deixaram de ocorrer. Coletaram-se apenas os ramos caidos, mas ligados às árvores vivas. Para esta amostragem, não foram coletados troncos soltos, pois estando nas margens do rio, esses troncos são facilmente carregados pela correnteza, mesmo esta sendo fraca. 
Em todas as coletas foram realizadas medidas de salinidade da água superficial dos rios em vários pontos, e da água de poças no interior dos bosques, durante a maré baixa. Os pontos amostrados foram numerados de 1 a $15 \mathrm{e}$ estão indicados na Figura 1.

Valores de salinidade da água superficial durante a maré alta foram obtidos semanalmente, de setembro a dezembro de 1984, para o ponto $1 \mathrm{e}$, em apenas duas coletas, uma em novembro e outra em dezembro de 1985 para os pontos 6,8 e 12 (Fig. 1).

A determinação dos valores de salinidade foi feita utilizando-se um refratômetro "Goldberg T/C", modelo 10419, da "American Optical".

Os animais foram retirados da madeira com o auxilio de facas, facão e pinças, anestesiados com propileno

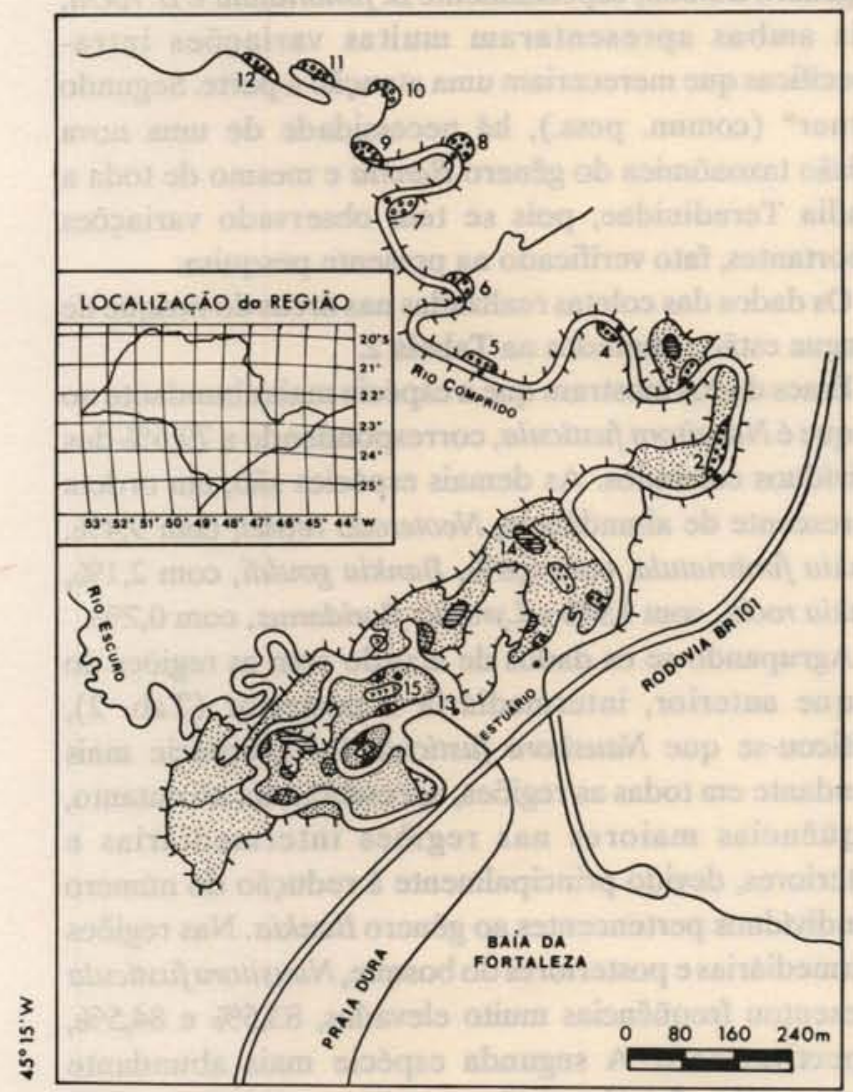

$23^{\circ} 30^{\prime} \mathrm{S}$

Fig. 1. Localização, regiōes de coleta e mapa do manguezal da Praia Dura, Ubatuba, SP. 图 manguezal; 团 zona de contato entre o manguezal ou rio e vegetação de transição; 圈 áreas marginais; 圂 áreas intermediárias;

苜; áreas posteriores; 圆 áreas ao longo das margens do Rio Comprido (1 a 12); os pontos 1 a 15 localizam onde foram feitas medidas de salinidade da água. fenoxetol e colocados em álcool glicerinado (5 partes de álcool $85 \%$ para 1 parte de glicerina líquida comercial).

Como o processo de retirada dos animais da madeira fragmentava muitos espécimes, a contagem do número de indivíduos nos diferentes locais de coleta foi feita somando-se o número de indivíduos completos removidos, com o número de regiōes posteriores do corpo dos fragmentados, contendo as paletas. Não foram consideradas as outras porçōes do corpo, evitando-se, assim, problemas de identificação específica.

A freqüência relativa das espécies no bosque de mangue foi calculada, dividindo-se o total de indivíduos de uma espécie pelo total de indivíduos de todas as espécies encontradas, Determinou- se também a freqüência relativa das espécies para cada local de coleta.

A identificação das espécies foi feita, principalmente, com base nos trabalhos de Clench \& Turner (1946) e Turner $(1966,1971 \mathrm{a})$.

\section{Resultados}

Observando-se a Figura 2 que resume os valores médios de salinidade da água superficial do Rio Comprido na maré baixa, pode-se notar um gradiente decrescente de salinidade entre os pontos 1 e 12 . No ponto 1 a salinidade variou de 0,0 a $15,0 \mathrm{~S}$, com valor médio de $6,4 \mathrm{~S}$; no ponto 2 variou de 0,0 a $5,0 \mathrm{~S}$, com valor médio de $1,7 \mathrm{~S}$; no ponto 3 variou de 0,0 a $5,0 \mathrm{~S}$, com valor médio de $1,5 \mathrm{~S}$; no ponto 4 variou de 0,0 a $4,0 \mathrm{~S}$, com valor médio de $1,2 \mathrm{~S}$; nos pontos 5 a 10 variou de 0,0 a $2,0 \mathrm{~S}$, com valor médio de $0,5 \mathrm{~S}$; no ponto 11 variou de 0,0 a $1,0 \mathrm{~S}$, com valor médio de $0,2 \mathrm{~S}$, e no ponto 12 foi sempre $0,0 \mathrm{~S}$.

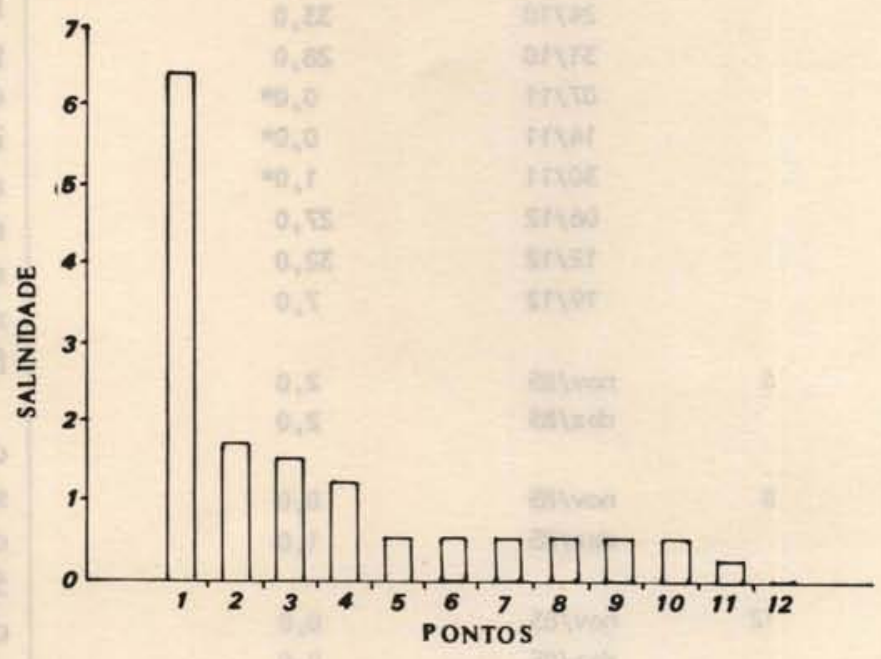

Fig. 2. Valores médios da salinidade da água superficial do Rio Comprido entre os pontos 1 e 12, durante as marés baixas. 
No Rio Escuro (no ponto 13), a salinidade variou de 0,0 a $5,0 \mathrm{~S}$, com valor médio de $1,5 \mathrm{~S}$. Os valores de salinidade obtidos em poças no interior do bosque (pontos 14 e 15) oscilaram de 2,0 a $30,0 \mathrm{~S}$ no ponto 14 , com valor médio de $13,5 \mathrm{~S}$ e de 0,0 a $24,0 \mathrm{~S}$ no ponto 15 , com valor médio de 10,6 S. Estes valores dão-nos uma idéia da salinidade da água que atinge essas regiōes do bosque durante as preamares. Não podem ser considerados valores exatos, pois essas poças estão sujeitas a dessecação.

As medidas semanais de salinidade da água superficial do Rio Comprido, durante a maré alta, no ponto 1, estão resumidas na Tabela 1. Desconsiderando-se as medidas feitas em dias chuvosos, quando a salinidade superficial diminui, observou-se que os valores variaram de 6,0 a 33,0 $\mathrm{S}$, com valor médio de $24,3 \mathrm{~S}$. Verificaram-se grandes variaçōes entre os valores de salinidade obtidos durante a maré baixa e os obtidos durante a maré alta de sizígia, variações estas típicas de regiōes estuarinas.

Os valores de salinidade da água superficial na maré alta, nos pontos $6,8 \mathrm{e} 12$ do Rio Comprido, estão resumidos na Tabela 1 e mostram que, no ponto 12 , não há mais influência da água do mar.

Tabela 1. Valores de salinidade da água superficial do Rio Comprido durante as marés altas

\begin{tabular}{|c|c|c|}
\hline Ponto & Data & $\begin{array}{l}\text { Sal inidade da água } \\
\text { superficial }\end{array}$ \\
\hline \multirow[t]{12}{*}{1} & $26 / 09$ & 26,0 \\
\hline & $04 / 10$ & 28,0 \\
\hline & $11 / 10$ & 32,0 \\
\hline & $18 / 10$ & 6,0 \\
\hline & $24 / 10$ & 33,0 \\
\hline & $31 / 10$ & 28,0 \\
\hline & $07 / 11$ & $0,0^{*}$ \\
\hline & $14 / 11$ & $0,0^{*}$ \\
\hline & $30 / 11$ & $1,0^{*}$ \\
\hline & $06 / 12$ & 27,0 \\
\hline & $12 / 12$ & 32,0 \\
\hline & $19 / 12$ & 7,0 \\
\hline \multirow[t]{2}{*}{6} & nov $/ 85$ & 2,0 \\
\hline & $\operatorname{dez} / 85$ & 2,0 \\
\hline \multirow[t]{2}{*}{8} & nov/85 & 0,0 \\
\hline & $\mathrm{dez} / 85$ & 1,0 \\
\hline \multirow[t]{2}{*}{12} & nov/85 & 0,0 \\
\hline & $\mathrm{dez} / 85$ & 0,0 \\
\hline
\end{tabular}

* Medidas feitas em dias chuvosos
As espécies de Teredinidae encontradas na área de estudo foram:

Subfamilia Teredininae Rafinesque, 1815

Neoteredo reynei (Bartsch, 1920) (Fig. 3A)

Psiloteredo healdi (Bartsch, 1931) (Fig. 3B)

Lyrodus floridanus (Bartsch, 1922) (Fig. 3C)

Subfamília Bankiinae Turner, 1966

Nausitora fusticula (Jeffreys, 1860) (Fig.3D)

Bankia rochi (Moll \& Roch, 1931) (Fig.4A)

Bankia fimbriatula (Moll, 1931) (Fig. 4B)

Bankia gouldi (Bartsch, 1908) (Fig. 4C)

Durante a identificação das espécies relacionadas na presente pesquisa, surgiram dificuldades com as espécies do gênero Bankia, especialmente $B$. fimbriatula e $B$. rochi, pois ambas apresentaram muitas variaçōes intraespecíficas que mereceriam uma atenção a parte. Segundo Turner* (comun. pess.), há necessidade de uma nova revisão taxonômica do gênero Bankia e mesmo de toda a família Teredinidae, pois se tem observado variaçōes importantes, fato verificado na presente pesquisa.

Os dados das coletas realizadas nas áreas do bosque de mangue estão resumidos na Tabela 2.

Esses dados mostram que a espécie mais abundante no bosque é Nausitora fusticula, correspondendo a 79,6\% dos indivíduos coletados. As demais espécies são, em ordem decrescente de abundância, Neoteredo reynei, com $9,4 \%$, Bankia fimbriatula, com 6,8\%, Bankia gouldi, com 2,1\%, Bankia rochi, com 1,9\% e Lyrodus floridanus, com 0,2\%.

Agrupando-se os dados de acordo com as regiōes do bosque anterior, intermediária e posterior (Tab. 2), verificou-se que Nausitora fusticula foi a espécie mais abundante em todas as regiōes, apresentando, no entanto, freqüências maiores nas regiōes intermediárias e posteriores, devido principalmente à redução do número de indivíduos pertencentes ao gênero Bankia. Nas regiöes intermediárias e posteriores do bosque, Nausitora fusticula apresentou freqüências muito elevadas, $83,5 \%$ e $84,5 \%$, respectivamente. A segunda espécie mais abundante nessas regiōes foi Neoteredo reynei, com $8,8 \%$ e $11,7 \%$, respectivamente. As demais espécies apresentaram freqüências iguais ou inferiores a $5 \%$.

$\mathrm{Na}$ margem do bosque, Nausitora fusticula correspondeu a $53,2 \%$ dos indivíduos, sendo que a segunda espécie mais abundante foi Bankia fimbriatula, com $24,6 \%$, seguida de B. gouldi, com $11,8 \%$, B. rochi, com $5,0 \%$, Neoteredo reynei, com $3,6 \%$ e Lyrodus floridanus, com $1,8 \%$.

(*) Turner, R. D. (1985) - Harvard University (EUA). 

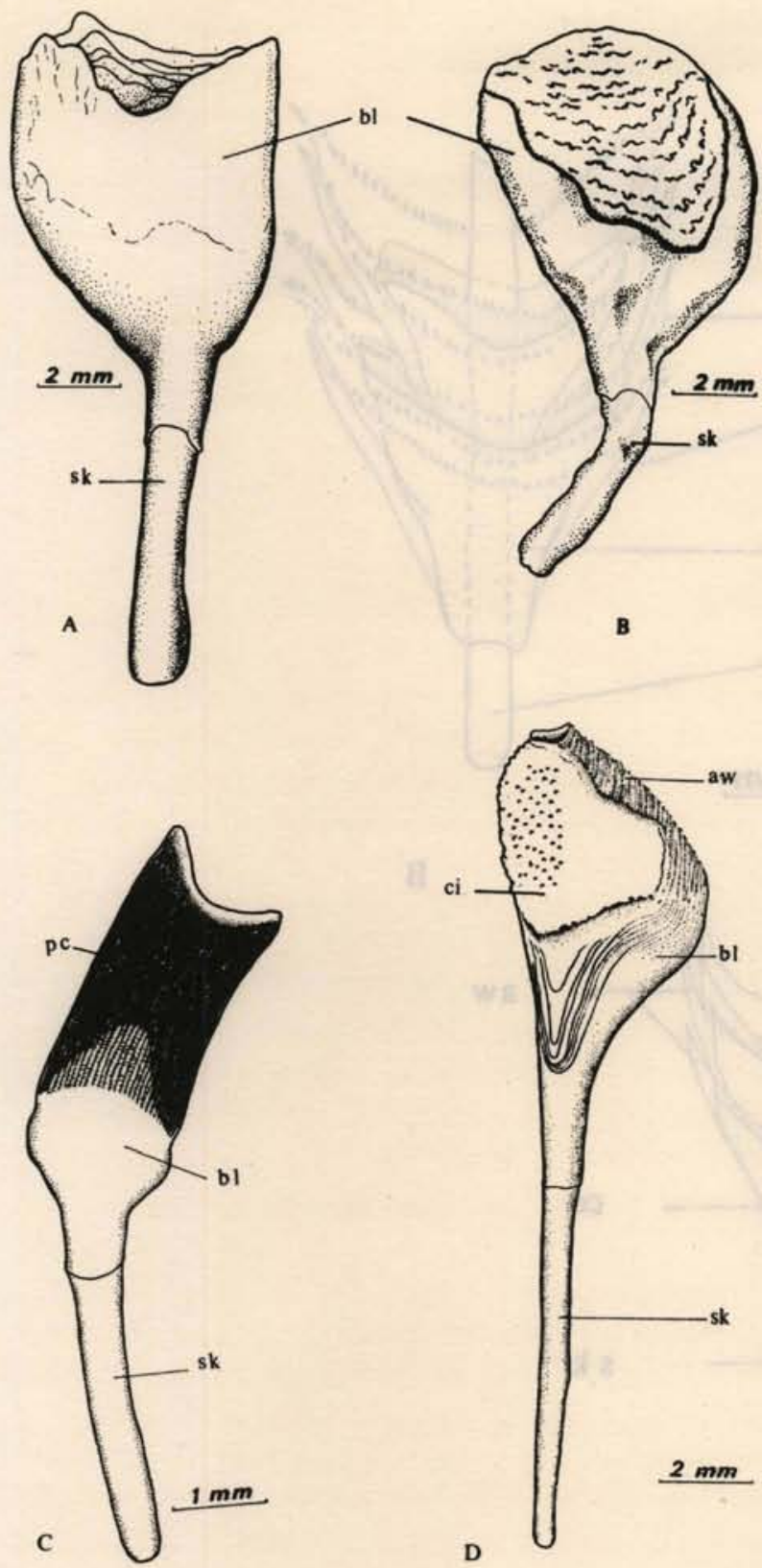

Fig. 3. Vista externa da paleta de espécies encontradas na região em estudo. A, Neoteredo reynei; B, Psiloteredo healdi; C, Lyrodus floridanus; D, Nausitoria fusticula. aw, aristas; bl, lâmina; ci, incrustação calcária; pc, carga de perióstraco; sk, pedúnculo.

Dados sobre a ocorrência e a distribuição das espécies de Teredinidae ao longo das margens do Rio Comprido, segundo um gradiente decrescente de salinidade, estão resumidos na Tabela 3. $\mathrm{Na}$ área 1 ocorreu número maior de espécies que nas demais. Essas espécies são, em ordem decrescente de abundância, Nausitora fusticula, com
$54,2 \%$, Bankia fimbriatula, com $31,7 \%$, Bankia rochi, com 7,5\%, Lyrodus floridanus, com 3,0\%, Bankia gouldi, com $2,5 \%$ e Neoteredo reynei, com $0,8 \%$. Nausitora fusticula ocorreu até a área 11, sendo a espécie mais abundante até a área 8; Neoteredo reynei ocorreu até a área 7, sendo a segunda espécie mais abundante no trecho de rio compreendido entre as áreas 2 e 7; Bankia fimbriatula e Bankia rochi ocorreram até a área 8, com poucos indivíduos; Bankia gouldi e Lyrodus floridanus ficaram restritos a área 1. Entre as áreas 7 e 11 registrou-se a presença de Psiloteredo healdi, espécie resistente a salinidades baixas, próximas de zero. Este é o primeiro registro da espécie para o Brasil. No trecho do rio compreendido entre as áreas 7 e 9, Psiloteredo healdi é a segunda espécie mais abundante, dividindo o ambiente com Nausitora fusticula; nas áreas 10 e 11, P. healdi passa a ser mais abundante. $\mathrm{Na}$ área 12 não foram mais encontrados exemplares de Teredinidae.

\section{Discussão}

As espécies do gênero Nausitora têm distribuição restrita a áreas de água salobra, em função principalmente da sensibilidade de suas larvas a salinidades mais altas; os adultos sobrevivem em águas com salinidades maiores e colonizam novas áreas quando as madeiras em se que encontram são transportadas por correntes marinhas até um novo local de água salobra, onde passam a se reproduzir normalmente (Turner, 1966; Saraswathy \& Nair, 1974).

Nausitora fusticula foi a espécie mais abundante no bosque de mangue e em quase todas as áreas amostradas segundo um gradiente decrescente de salinidade, ao longo das margens do Rio Comprido. Esses dados sugerem que essa espécie está bem adaptada ao ambiente entremarés e a grandes variaçōes de salinidade. Na região em que $N$. fusticula ocorreu, a salinidade variou de 0,0 a 30,0 S.

Dentre as demais espécies encontradas juntamente $\operatorname{com} N$. fusticula na região do bósque de mangue, Neoteredo reynei ocorreu preferencialmente em madeiras coletadas em áreas recobertas menos freqüentemente pela água do mar na maré alta, apresentando baixa freqüência em madeiras coletadas nas margens do bosque. Lyrodus floridanus e as espécies do gênero Bankia, ao contrário de Neoteredo reynei, mostraram preferência pelas áreas do bosque mais freqüentemente recobertas pela água do mar. Dentre as espécies registradas no presente trabalho, tem-se informação sobre a resistência à exposição ao ar somente para $L$. floridanus, correspondendo a 56 horas de emersão, com intervalo de confiança de mais ou menos 14 horas (Omena et al.,1990). 


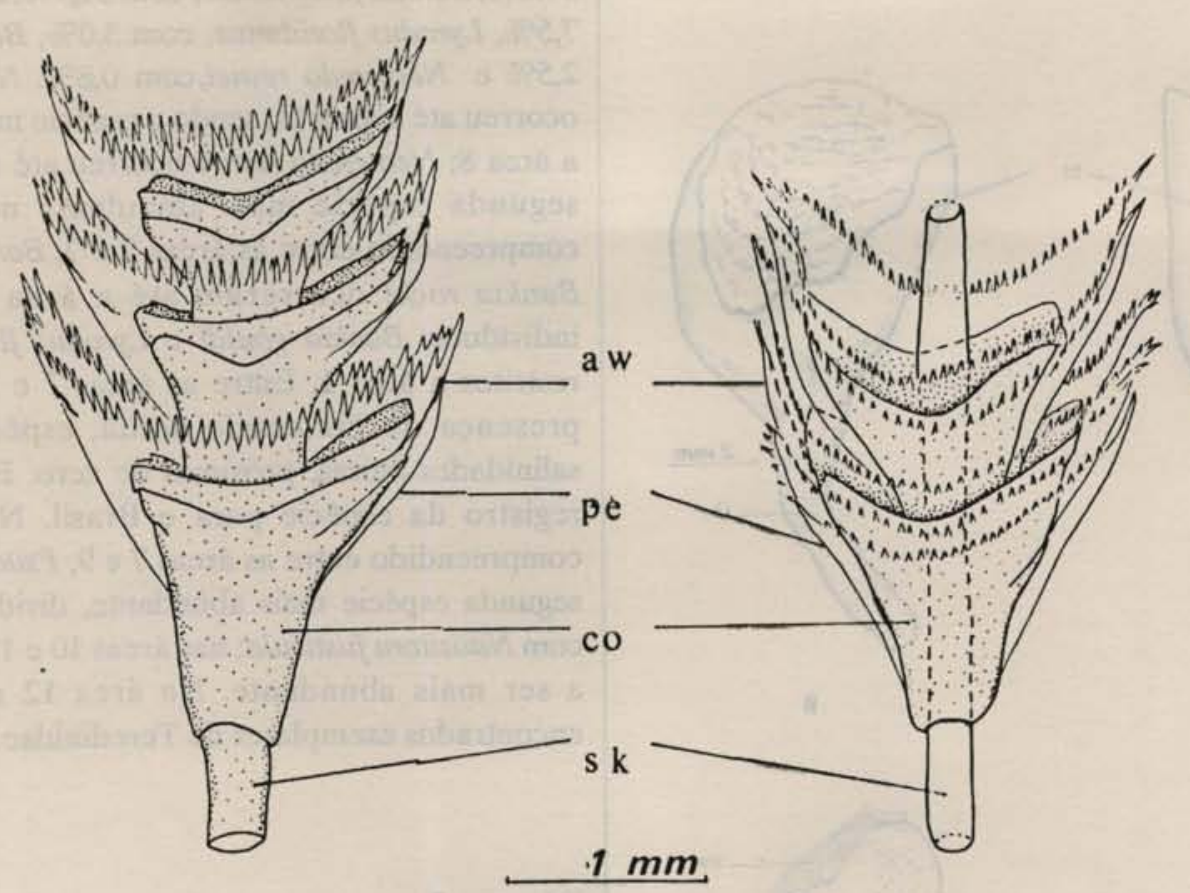

A

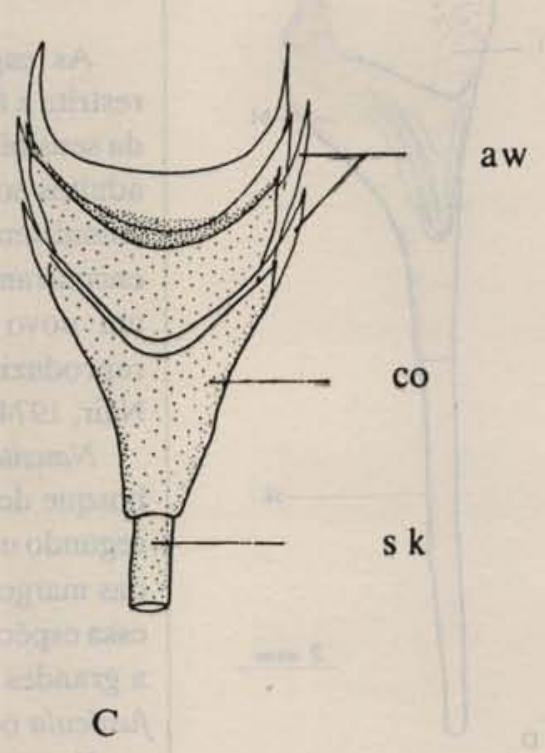

B

Fig. 4. Paletas, em vista externa, de três espécies da subfamflia Bankiinae encontradas na região em estudo. A, Bankia rochi; B, Bankia fimbriatula; C, Bankia gouldi; aw, aristas (projeções laterais do perióstraco, com extremidades distais afiladas); co, cone calcário; pe, perióstraco, sk, pedúnculo.

Nausitora fusticula e Neoteredoreynei podem, portanto, permanecer por intervalos maiores de tempo fora do contato com a água, enquanto que $L$. floridanus e as espécies de Bankia, apesar de estarem adaptadas a ambiente entremarés, devem necessitar imersōes mais freqüentes. Não só os adultos, mas principalmente as larvas dessas espécies provavelmente diferem na resistência à dessecação. A fase larval é crítica na vida desses animais, pois é mais sensível às variaçōes do meio.
Para os Teredinidae, também é importante o momento do assentamento e o da penetração na madeira. Em ambiente de manguezal associado a estuário, as variaçōes de salinidade da água são grandes e a fauna bêntica fica exposta ao ar por períodos consideráveis de tempo, pois os bosques de mangue desenvolvem-se do médio litoral superior ao supra-litoral. Desse modo, as larvas dessas espécies devem estar adaptadas a grandes variaçōes de salinidade, que são típicas de regiōes estuarinas e, no 
Tabela 2. Número total de indivíduos (№) e freqüência relativa (\%) das diferentes espécies de Teredinidae no bosque de mangue e em suas regiōes

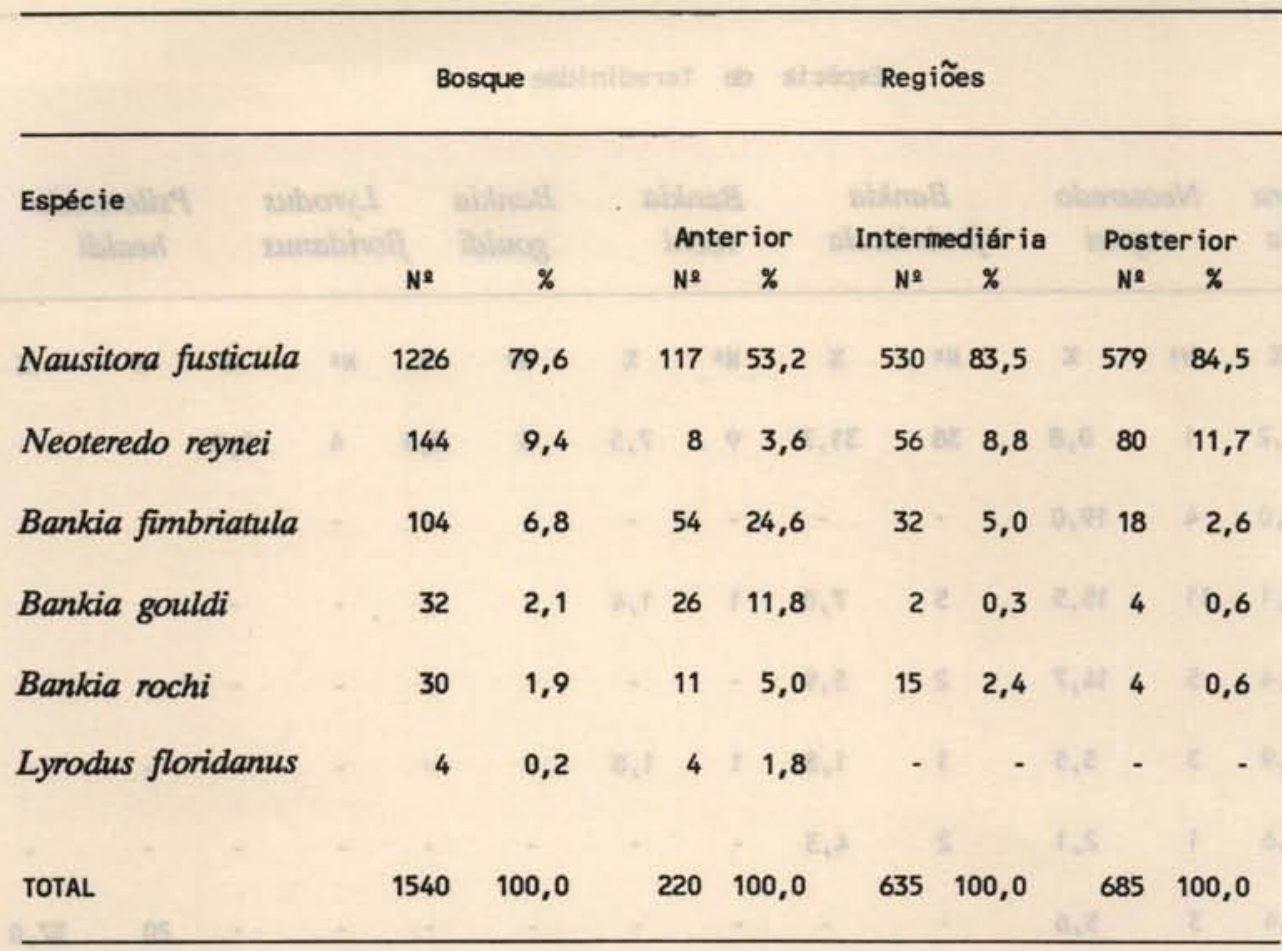

período de assentamento, a ficar expostas ao ar durante as marés baixas, principalmente se instaladas em madeiras encontradas nas porçōes mais internas do bosque. As larvas de $N$. fusticula e de Neoteredo reynei provavelmente suportam melhor essas condições do que larvas das demais espécies.

A duração do período larval dos Teredinidae no plâncton, varia de algumas horas a dez semanas, dependendo da espécie e do tipo de padrão reprodutivo, que podem ser três (Turner, 1971b): espécies ovíparas, larvíparas de curto período de incubação larval e larvíparas de longo período de incubação larval. As espécies larvíparas, por apresentarem período de vida planctônica mais curto que as ovíparas, têm geralmente maiores chances de sucesso reprodutivo, pois suas larvas permanecem tempo menor em exposiçāo às variáveis do meio, numa fase bastante sensível do ciclo vital; em função disso, quando presentes em um ambiente, geralmente são as mais abundantes (Turner, 1984).

Dentre as espécies encontradas na área em estudo, apenas Lyrodus floridanus é larvípara e do tipo de curto período de incubaçāo larval. As demais, são ovíparas. $O$ número de indivíduos de $L$. floridanus, no entanto, foi pequeno, comparando aos das espécies ovíparas. Nestes casos particulares em que predominam indivíduos das espécies ovíparas e não das larvíparas como é mais comum quando presentes em uma regiāo, é provavel que, apesar de terem período de vida planctônica maior, suas larvas estejam melhor adaptadas que as das espécies larvíparas, às condiçōes variáveis do ambiente estuarino e das regiōes entremarés. Eckelbarger \& Reish (1972) forneceram a resistência a salinidade de larvas de algumas espécies de Teredinidae porém nenhuma das espécies citadas foi encontrada na presente pesquisa. Entretanto, esses autores deram dados sobre $L$. pedicellatus, espécie que se diferencia de L. floridanus apenas pelo ciclo sexual e que vive dentro do mesmo gradiente ecológico. As larvas de $L$. pedicellatus sobrevivem até um mínimo de $20 \mathrm{~S}$. Na regiāo em estudo, a salinidade atinge valores inferiores a $20 \mathrm{~S}$ e esse fato provavelmente interfere na sobrevivência das larvas de $L$. floridanus, explicando porque não é tão abundante na região.

Vencida a fase planctônica, os Teredinidae enfrentam ainda outras etapas críticas à sobrevivência, como a do assentamento, a metamorfose e a do início da penetração na madeira. $O$ assentamento ocorre quando a larva se encontra no estádio de pedivéliger. Uma vez localizado o substrato adequado, o pedivéliger sobre metamorfose e inicia a perfuração da madeira. Dentre as espécies encontradas na área em estudo, conhece-se o tempo decorrido entre o momento do assentamento e o da penetração na madeira, apenas para B. gouldi: dois dias (Clench \& Turner, 1946). Em ambiente de manguezal, a probabilidade da larva ficar exposta ao ar durante as marés baixas é muito grande, especialmente se estiver em madeiras encontradas nas porçōes mais internas do 
Tabela 3. Número de indivíduos (№) e frequeência relativa (\%) das diferentes espécies de Teredinidae encontradas nas áreas 1 a 12 amostradas ao longo das margens do Rio Comprido.

Espécie de Teredinidae

\begin{tabular}{|c|c|c|c|c|c|c|c|}
\hline $\begin{array}{l}\text { Nausitora } \\
\text { fusticula }\end{array}$ & $\begin{array}{c}\text { Neoteredo } \\
\text { reynei }\end{array}$ & $\begin{array}{c}\text { Bankia } \\
\text { fimbriatula }\end{array}$ & $\begin{array}{l}\text { Bankia } \\
\text { rochi }\end{array}$ & $\begin{array}{l}\text { Bankia } \\
\text { gouldi }\end{array}$ & $\begin{array}{l}\text { Lyrodus } \\
\text { floridanus }\end{array}$ & $\begin{array}{l}\text { Psiloteredo } \\
\text { healdi }\end{array}$ & $\begin{array}{l}\text { Total de } \\
\text { indivíduos/área }\end{array}$ \\
\hline
\end{tabular}

\begin{tabular}{lllllllllllllllll} 
ÁREA & $N^{2}$ & $\%$ & $N^{2}$ & $\%$ & $N^{2}$ & $\%$ & $N^{2}$ & $\%$ & $N^{2}$ & $\%$ & $N^{2}$ & $\%$ & $N^{2}$ & $\%$ & & \\
01 & 65 & 54,2 & 1 & 0,8 & 38 & 31,7 & 9 & 7,5 & 3 & 2,5 & 4 & 3,0 & - & - & 120 \\
02 & 17 & 81,0 & 4 & 19,0 & - & - & - & - & - & - & - & - & - & - & 21 \\
03 & 54 & 76,1 & 11 & 15,5 & 5 & 7,0 & 1 & 1,4 & - & - & - & - & - & - & 71 \\
04 & 27 & 79,4 & 5 & 14,7 & 2 & 5,9 & - & - & - & - & - & - & - & - & 34 \\
05 & 50 & 90,9 & 3 & 5,5 & 1 & 1,8 & 1 & 1,8 & - & - & - & - & - & - & 55 \\
06 & 44 & 93,6 & 1 & 2,1 & 2 & 4,3 & - & - & - & - & - & - & - & - & 47 \\
07 & 31 & 57,4 & 3 & 5,6 & - & - & - & - & - & - & - & - & 20 & 37,0 & 54 \\
08 & 15 & 48,4 & - & - & 2 & 6,5 & 1 & 3,2 & - & - & - & - & 13 & 41,9 & 31 \\
09 & 5 & 71,4 & - & - & - & - & - & - & - & - & - & - & 2 & 28,6 & 7 \\
10 & 1 & 12,5 & - & - & - & - & - & - & - & - & - & - & 7 & 87,5 & 8 \\
11 & 1 & 16,7 & - & - & - & - & - & - & - & - & - & - & 5 & 83,3 & 6 \\
12 & - & - & - & - & - & - & - & - & - & - & - & - & - & - & - \\
\hline
\end{tabular}

bosque. Desse modo, as larvas no estádio de pedivéliger de $N$. fusticula e de Neoteredo reynei, provavelmente apresentam adaptaçōes que lhes permitam sobreviver a períodos maiores de exposição ao ar do que as das espécies de Bankia e $L$. floridanus.

A análise dos resultados sobre a ocorrência e distribuição das espécies, segundo um gradiente decrescente de salinidade, ao longo das margens do Rio Comprido, permite considerar quatro grandes regiōes em função da dominância entre as espécies : regiāo anterior (área 1), caracterizada pela dominância de $N$. fusticula Bankia fimbriatula; região média- anterior (áreas 2 a 6), caracterizada pela dominância de $N$. fusticula - Neoteredo reynei; regiāo média-posterior (áreas 7 a 9), caracterizada pela dominância de $N$. fusticula - P. healdi; regiāo posterior (áreas 10 e 11), caracterizada pela dominância de $P$. healdi - N. fusticula.
Além da madeira, que constitui o estímulo básico para o assentamento larval e o substrato no qual os Teredinidae vivem, a salinidade é um dos principais fatores que determina a distribuição das espécies dessa família. A presença de Teredinidae em um local, requer basicamente madeira e água do mar. Existem, no entanto, algumas espécies que ocorrem virtualmente em água doce, como é o caso de Teredo poculifer, Psiloteredo healdi e as espécies do gênero Nausitora (Hoagland \& Turner, 1981). Essas espécies, contudo, restringem-se somente a rios estuarinos, até o limite máximo da penetração da água do mar durante as preamares, nunca ocorrendo em corpos de água doce sem contato com o mar (Turner*, comun. pess.). Na região em estudo, os Teredinidae não foram encontrados a partir da área 11, sugerindo que esse é o

(*) Turner, R. D. (1985) - Harvard University (EUA). 
limite máximo de influência da água do mar. Os dados de salinidade obtidos para a água de superfície durante a maré alta no Rio Comprido, indicam que entre as áreas 8 e 12 ocorre a transição da água salobra para doce. Das espécies presentes nessa região posterior do rio, apenas $N$. fusticula e $P$. healdi ocorrem até a área 11, indicando que são mais resistentes a salinidades baixas que as demais.

Bankia fimbriatula é uma espécie eurialina, que suporta salinidades entre 5 e 35 S (Junqueira \& Silva, 1991; Junqueira et al., 1989). No presente trabalho, B. fimbriatula deixou de ocorrer em locais onde a salinidade era constantemente baixa, coincidindo com os dados dos trabalhos citados. Das demais espécies registradas para o local de estudo, existem dados na literatura consultada sobre resistência à salinidade apenas para $B$. rochi, $B$. gouldi e L. floridanus: a primeira, segundo Rayner (1979) e a segunda, de acordo com Turner (1974), sobrevivem bem em salinidades que variam de 10 a $35 \mathrm{~S}$; a terceira ocorre em locais com salinidades que variam de 17 a $35 \mathrm{~S}$ (Junqueira \& Silva, 1991). No presente trabalho, B. gouldi e $L$. floridanus ficaram restritas às regiōes do estuário com salinidades mais elevadas, o que também foi constatado por Müller \& Lana $(1986,1987)$ para a regiảo de Paranaguá, no Estado do Paraná, Brasil. B. rochi, no entanto, ocorreu em locais com salinidades inferiores ao valor mencionado como limite mínimo para sua sobrevivência. Estudos sobre a resistência das espécies que ocorrem no manguezal da Praia Dura em relação aos fatores salinidade e dessecação, se fazem necessários para corroborar o padrāo de distribuiçāo verificado no presente trabalho.

\section{Conclusões}

A espécie mais abundante em toda área estudada foi Nausitora fusticula, perdendo sua dominância para Psiloteredo healdi nas áreas de salinidade mais constantemente próximas a $0 \mathrm{~S}$. No bosque de mangue podem ser definidas duas regiōes em função da dominância das espécies. A primeira em contato mais constante com a água caracterizada pela dominância de $N$. fusticula e de Bankia fimbriatula e a segunda recoberta menos freqüentemente pelas preamares, caracterizada pela dominância de $N$. fusticula e de Neoteredo reynei.

Segundo um gradiente decrescente de salinidade ao longo do curso do Rio Comprido, puderam ser definidas quatro regiōes em funcāo da dominância das espécies encontradas, a saber : anterior - $N$. fusticula e $B$. fimbriatula, onde a salinidade variou de $33,0 \mathrm{a} 0,0 \mathrm{~S}$; médiaanterior - N. fusticula e Neoteredo reynei, onde a salinidade variou de 5,0 a $0,0 \mathrm{~S}$; média-posterior - $N$. fusticula e Psiloteredo healdi, onde a salinidade variou de 2,0 a $0,0 \mathrm{~S}$; posterior - $P$. healdi e $N$. fusticula, onde a salinidade variou de 1,0 a $0,0 \mathrm{~S}$.

\section{Agradecimentos}

Agradecemos à Fundação de Amparo à Pesquisa do Estado de São Paulo (FAPESP) que financiou o presente trabalho, através dos Processos No 84/0486 e 84/1020-0 e à Base Norte do Instituto Oceanográfico da USP, onde realizou-se parte das atividades de campo.

\section{Referências bibliográficas}

ABBOTT, R.T. 1974. American seashells. $2^{\text {nd }}$ ed. New York, Van Nostrand Reinhold. 663p.

BARTSCH, P. 1922. A monograph of the American shipworms. Bull.U. S. natn. Mus., 122:1-51.

BOFFI, A.V. 1979 Moluscos brasileiros de interesse médico e econômico. São Paulo, FAPESP. 182p.

CLENCH, W. J. \& TURNER, R. D. 1946 The genus Bankia in the Western Atlantic. Johnsonia, 2:1-28.

ECKELBARGER, K. J. \& REISH, D. S. 1972. A first report of self-fertilization in the wood-boring family Teredinidae (Mollusca - Bivalvia). Bull. south. Calif. Acad. Sci., 71:48-50.

HERZ, R. 1991 Manguezais do Brasil. São Paulo, Instituto Oceanográfico da Universidade de São Paulo.

HOAGLAND, K. E. \& TURNER, R. D. 1981. Evolution and adaptation radiation of wood-boring bivalves (Pholadacea): Malacologia, 21(1/2):111-148.

JUNQUEIRA, A. O. R. \& SILVA, S. H. G. 1991. Estudo experimental dos Teredinidae Rafinesque 1815 (Mollusca - Bivalvia) do estuário da Lagoa da Tijuca, Rio. Revta brasil. Biol., 51(1):113- 126.

MARTINS-SILVA, M. J. 1989. Avaliação da infestação e diversidade de Teredinidae (Mollusca - Bivalvia) ao longo da costa do Estado do Rio de Janeiro, Brasil. Mems. Inst. Oswaldo Cruz, Rio de Janeiro, 81:275-280. Suplemento 4.

LANE, C. E. 1955. Recent biological studies on Teredo, a marine wood-boring molluscs. Sci. Mon., NY, $80(5): 286-292$. 
KINNE, O. 1963. The effects of temperature and salinity on marine and brackish water animals. II. Salinity and temperature combinations. Oceanogr. mar. Biol. a. Rev., 2:281-339.

MARTINS-SILVA, M. J.; JUNQUEIRA, A. O. R \& SILVA, S. H. G. 1990. Distribuição dos organismos marinhos perfurantes de madeira, segundo um gradiente crescente de salinidade, no canal de Itajuru, Cabo Frio, Rio de Janeiro, Brasil. In: SIMPÓSIO DE ECOSSISTEMAS DA COSTA SUL E SUDESTE BRASILEIRA: ESTRUTURA, FUNÇĀO E MANEJO, 2., Águas de Lindóia, 1990. São Paulo, Academia de Ciências do Estado de São Paulo. v.2, p.264-272.

; SILVA, S. H. G. \& JUNQUEIRA, A. O.R. 1988. Distribuição vertical de Teredinidae (Mollusca:Bivalvia) em Portogallo, Angra dos Reis, Rio de Janeiro, Brasil. Revta brasil. Zool., S Paulo, 5(1):155-165.

MÜLLER, A. C. P. \& LANA, P. C. 1986 Teredinidae (Mollusca: Bivalvia) do litoral do Paraná. Nerítica, Pontal do Sul, 1(3):27-48.

\& 1987.

Padrões de distribuição geográfica de Teredinidae (Bivalvia: Mollusca) do Estado do Paraná. Ciênc. Cult., S Paulo, 39:1175- 1177.

NAIR, N. B. \& SARASWATHY, M. 1971. The biology of wood-boring teredinid molluscs. Adv. mar. Biol., 9:335-509.

OMENA, E. P.; JUNQUEIRA, A. O. R. \& SILVA, S. H. G. 1990. Resistência de Teredinidae Rafinesque 1815 (Mollusca - Bivalvia) a diferentes períodos de exposição ao ar. Revta brasil. Biol., 50(3):701-707.

RAYNER, S. M. 1979. Comparison of the salinity range tolerated by teredinids (Mollusca - Teredinidae) under controlled conditions with that observed in an estuary in Papua New Guinea. Aust. J. mar. Freshwat. Res., 30(4):521-533.
RIOS, E. C. 1985 . Seashells of Brazil. Rio Grande, Fundação Cidade do Rio Grande/Fundação Universidade do Rio Grande/Museu Oceanográfico. 328 p.

SARASWATHY, M. \& NAIR, N. B. 1974. The influence of salinity on a tropical estuarine shipworm Nausitora hedleyi Schepman (BivalviaTeredinidae). Hidrobiologia, 44(4):397-411.

SILVA, S. H. G.; JUNQUEIRA, A. O. R.; MARTINS-SILVA, M. J.; ZALMON, I. R. \& LAVRADO, H. P. 1989. Fouling and woodboring communities distribution on the coast of Rio de Janeiro. In: SYMPOSIUM ON COASTAL AND OCEAN MANAGEMENT, 6., Charleston, 1989. Neves, C., ed. Coastlines of Brazil. New York, American Society of Civil Engineers. p. 95-109.

TURNER, R. D. 1966. A survey and illustrated catalogue of the Teredinidae (Mollusca: Bivalvia). Cambridge, The Museum of Comparative Zoology. 265 p.

1971a. Identification of marine-boring molluscs. In: Jones, E. B. G. \& Eltringham, S. K., eds Marine borers, fungi and fouling organisms of wood. Paris, Organization for Economic Co-operation and Development. p.17-64.

1971b. Australian shipworms. Aust. Nat. Hist., Sydney, 17:139-145.

1974. In the path of a warm, saline effluent. Am. Malac. Union. Bull, 39:36-41.

1984. An overview of research on marine borers: past, progress and future direction. In: Costlow, S. D. \& Tipper, R. C., eds Marine biodeterioration: an interdisciplinary study. Annapolis, Naval Institute Press. p.3-16.

(Manuscrito recebido 26 janeiro 1993; revisto 25 outubro 1993; aceito 29 outubro 1993) 